\title{
A desescolarização da sociedade para a construção do conhecimento ${ }^{1}$ \\ Miguel Sgarbi PACHIONI ${ }^{2}$
}

Illich, Ivan. Sociedade sem escolas: trad. de Lúcia Mathilde Endlich Orth. Petrópolis, Vozes, 1985. I88p. (Educação e tempo presente, 10).

\section{RESUMO}

O presente texto apresenta a resenha do livro "Sociedade sem escolas", do polímata pensador austríaco Ivan Illich. Nesta obra, publicada originalmente em 1971, o modelo de disciplina escolar universal, amplamente adotado no ocidente, é confrontado com a possibilidade de se desescolarizar as instituições e o modelo de aprendizagem para que, assim, tenha-se a possibilidade de compactuar a verdadeira potencialidade criativa dos educandos com suas habilidades. Com isso, fica evidente a razão pelo qual o autor estrutura seu pensamento em direção a natureza da aprendizagem, para quem educar não é escolarizar e não se faz para todos, mas sim por todos.

Nascido em Viena em 1926, Ivan Illich é autor de muitas obras e artigos que, em uma visão geral, tratam de questionar e contestar muitas das instituições e estruturas sociais existentes (e consolidadas) ao longo do século XX. A obra "Sociedade sem Escolas", publicada em 1971, foi uma das que mais provocou inquietações na opinião pública, com reflexões ainda pertinentes na atualidade, desenvolve o tema da desescolarização.

Já nas primeiras páginas da obra fica evidente seu posicionamento sobre a impossibilidade de uma educação universal através da escola. Tendo como premissa sua insatisfação com a conjuntura do sistema educacional existente, principalmente pelo fato de as instituições de ensino terem se tornado burocráticas e hierarquizadoras distanciando-se do ideal de levar cada indivíduo a transformar suas próprias experiências e referências em um contínuo processo de aprendizado, Illich sugere a criação de um sistema alternativo e procura justificar tal proposta refletindo sobre as

\footnotetext{
${ }^{1}$ Trabalho apresentado à quarta edição da Revista Ação Midiática - Estudo em Comunicação, Sociedade e Cultura, publicação esta ligada ao Programa de Pós-Graduação em Comunicação da Universidade Federal do Paraná.

${ }^{2}$ Publicitário, especialista em Marketing e em Turismo, mestrando em Comunicação e Sociedade pela Universidade Federal do Paraná. Email: miguelsgarbi@ hotmail.com
} 
inúmeras iniciativas educacionais insensatas que, ao longo dos anos, foram (e ainda são) incorporados à educação formal.

Nesse sentido, o autor questiona o sistema que impõe a todos o acesso e usufruto de uma educação que, diante do desenvolvimento das relações sócioeconômicas associadas às transações comerciais, está diretamente ligada e dominada pela visão da educação como um produto pré-formatado. Assim, enquanto os alunos tornam-se escolarizados e são levados a confundir ensino com aprendizagem, obtenção de graus com educação, os professores se habituam a transmissão de conteúdo e não à construção de conhecimento, vêem-se incapazes de abordar e aprofundar temas relevantes para a realidade vivenciada localmente, ignorando a individualidade e submetendo-a ao senso comum do pensamento institucionalizado.

\section{O fracasso do modelo escolar: seu reducionismo}

A necessidade de se "desinstalar" a escola, para o autor, reside no fato da mesma limitar a imaginação dos educandos que, inseridos no ambiente escolar homogeneizador do pensamento, passam a aceitar serviço ao invés de valor. Para o autor a escola baseia-se na condição de que a aprendizagem é o resultado do ensino e a sabedoria institucionalizada continua a aceitar esta postura, apesar das de evidências provarem o contrário. Com isso, não somente a educação, mas a própria realidade social tornou-se escolarizada - é justamente devido ao monopólio do pensamento advindo da institucionalização da vida que reside a raiz da "modernização da pobreza". Esta, por sua vez, é um fenômeno universal e propicia o subdesenvolvimento à medida que combina "a falta de poder sobre as circunstâncias com a perda de força pessoal" (p.18).

Illich relata que a maioria dos países latino-americanos encontra-se "amarrado" a este sistema escolar que raramente possibilita a uma criança pobre nivelar-se a uma criança rica em termos de conhecimento, mesmo que ambas frequentem escolas de qualidade similar porque as oportunidades educacionais que a criança da classe média possui não se equiparam às da criança pobre que "ficará em desvantagem porquanto depende da escola para progredir ou aprender" (p.21), assim percebe-se que o modelo escolar se embasa cada vez mais em uma visão técnica da educação, como fornecedora de mão de obra produtiva para sanar a demanda industrial existente ao mesmo tempo em que seu currículo privilegia a iniciação para uma sociedade de consumo. Nesse 
sentido, Gramsci (1968) postula as diferenças entre a formação científica e humanística para as elites e o treinamento técnico voltado para o trabalho destinado às classes populares.

Como o aprendizado relaciona-se com a aquisição de nova habilidade ou compreensão, a escola distancia-se dessa proposta por privilegiar um saber contínuo da opinião alheia, reaplicado em um contexto adverso, não experienciado. Assim, a escolaridade não está apta a promover a justiça e nem mesmo a aprendizagem porque fornece apenas instrução, sem vincular sua relevância ou as competências compartilhadas. Tal prerrogativa encontra em Freire (1996) seu contraponto quando este autor afirma que todo aprendizado deve se encontrar intimamente associado à tomada de consciência da situação real vivida pelo educando. Esquece-se, então, que grande parte da aprendizagem relacionada à formação de um ser humano acontece espontaneamente, fora da escola, e mesmo a transferência intencional de conhecimento não advém de uma instrução programada. Por isso, Illich sugere que a desescolarização da sociedade implicaria no reconhecimento da dupla natureza da aprendizagem, de se aprender habilidades e de se obter competências para aplicá-las. A escola, porém, realiza mal ambas as tarefas em parte, por não saber distingui-las.

Pensamentos paradoxais apresentados pelo autor surgem da convicção de países em que menos pessoas foram servidas por escolas e de que a escolarização universal é absolutamente necessária, ainda que economicamente seja impraticável. Além disso, quanto maiores os gastos com a educação, maior sua destrutividade tanto para a família como para a nação.

Tal enredo permite uma dupla exploração: ao passo em que permite uma crescente aplicação de verbas públicas para a educação (qualificada) de uns poucos, subordina-se ao controle social instaurado por este sistema institucionalizado. Consequentemente, em qualquer realidade na qual a pobreza seja objeto de estudo, notase que a mera existência de escolas desencoraja os pobres de assumir o controle da própria aprendizagem - os fracassos da escola residem, portanto, em sua redução, tornando a sociedade polarizada.

É notável que a igualdade de oportunidade na educação seja uma meta desejável e Illich afirma ser alcançável, mas o autor destaca que não se pode confundi-la com o regime de obrigatoriedade escolar, ou seja, a escolarização não pode se tornar um fim em si mesmo. Para tanto, sugere que o ensino de habilidades esteja desvinculado de 


\section{REVISTA AÇÃOMIDIÁTICA - Estudos em Comunicação, Sociedade e Cultura}

Universidade Federal do Paraná

Programa de Pós Graduação em Comunicação

Vol 2. No 2. Ano 2012

grades curriculares e a educação, dissociada da frequência obrigatória - a premissa não seria uma educação para todos, mas sim uma educação por todos, em que cada indivíduo teria o direito de exercer sua competência para aprender e se instruir. Disso resulta a necessidade do homem moderno em aprender a encontrar sentido em muitas estruturas às quais está ligado apenas marginalmente.

Illich elege como maior obstáculo para atingir uma sociedade que realmente eduque, em contraposição à dialética da educação que se torna não-do-mundo e o mundo que se torna não-educativo, o fato de o imaginário existente estar condicionado ao pensamento escolarizado. Como saída, sugere que a avaliação do nível da instituição educacional de uma dada sociedade seja exatamente o grau de sua participação efetiva (política), isto é, no modo como os indivíduos relacionam-se com as esferas que os representam (ou governam). Para isso, a desescolarização da educação depende da liderança dos que foram criados na escola.

\section{Universidade como mera continuidade}

Com o desenrolar da vida, naturalmente a perspectiva vivenciada na escola tem continuidade na formação superior, sistema este que é economicamente exorbitante e ainda assim falho, pois o universitário escolariza-se para exercer funções seletas entre os ricos do mundo. Assim, o aparato alienador promovido pelo sistema educacional perpetua-se, promovendo padrões de consumo, formas de conduta e modelos de pensamento que se subordinam à demanda mercadológica, separando educação de realidade e trabalho de criatividade, algo um tanto recente.

$\mathrm{Na}$ idade média, a universidade valia-se do direito individual de se expressar, era uma comunidade de pesquisa e de inquietude, mas este conhecimento não se traduzia em riqueza - ser um "escolar" significava ser pobre. Tal concepção difere da finalidade estrutural moderna, que administra o saber como um processo fabricador de pesquisa, sendo o estudo visto como objeto de anseios em duas perspectivas complementares: enquanto aos estudantes representa um promissor futuro financeiro, aos países é considerado o medidor de seu desenvolvimento.

Para Illich, então, o sistema escolar desempenha uma tríplice função que, em consonância com o posicionamento da igreja ao longo da história, fora implementado em seu tempo vigente: é, ao mesmo tempo, o repositório do mito da sociedade; a 
institucionalização das contradições desse mito; e o lugar do rito que reproduz e envolve as disparidades entre mito e realidade. Isto dito, o autor conclui que uma verdadeira reforma educacional deve ocorrer, sendo propícia somente quando compreendido que nem a aprendizagem individual nem a igualdade social podem ser incrementadas pelo rito escolar.

Tal rito traduz-se no mito moderno de que a escolarização produz valor e, com isso, a produção cria a demanda e move o mercado. Por se acreditar, na e pela escola, que a instrução produza aprendizagem, sua mera existência produz a demanda pela escolarização que, por sua vez, cria uma aprendizagem fragmentada que é resultado da repetição e não da compreensão. Reforça-se assim um ciclo vicioso em que, pelo fato de o valor da aprendizagem aumentar proporcionalmente no decorrer do tempo, ele é mensurado por certificados que passam a ter peso, reforçando a rivalidade entre os pares para que a felicidade se encontre no seu consumo inesgotável. Logo, todas as escolas são obrigatórias, intermináveis e competitivas.

Confunde-se, assim, a aprendizagem como um processo externalizado, resultado da instrução alheia que condiciona o pensamento e limita a imaginação, sem considerá-la resultado de participação aberta em situações significativas. Assemelhando-se às maquinas, as "ex-pectativas" substituem a esperança pois os ensinamentos são repassados de forma descontextualizada, desencorajando novas iniciativas e praticamente eliminando o despertar da curiosidade. Portanto, com a transferência da responsabilidade do ser-humano para a instituição, emerge a regressão social, ainda mais quando aceita como obrigação e formatada segundo um modelo focado na venda de currículo e conteúdo, sem proporcionar a alegria de conhecer e se envolver com algo integralmente.

\section{Educar não é escolarizar e se faz pelo professor}

Mesmo que a escola não seja a única instituição moderna que restrinja a visão humana da realidade, ela o faz de forma mais profunda pelo fato de a ela estar creditada a função primordial de formar a capacidade crítica, ainda que, nos moldes atuais, a aprendizagem dela provinda dependa de um processo pré-empacotado. Além disso, a escola tornou-se o maior e mais anônimo empregador, sucedendo as corporações em 
similaridade com estas, sendo considerada uma variável da estrutura política e econômica de uma determinada sociedade.

Illich sugere que, desde o início do século XX, sob o impacto da intensa urbanização, a criança tornou-se uma fonte a ser moldada pelas escolas e a servir de alimento para a máquina industrial. Referenciando-se à Dewey (1952), a quem considerava um defensor do verdadeiro conhecimento - construído através de uma técnica que capacitava as pessoas a mudar o mundo em vez de amoldar-se a ele, propondo uma relação integradora e horizontalizada entre todos os envolvidos no processo de aprendizagem - o autor sugere a transformação de cada escola em um embrião comunitário que reflita em sua didática a vida da sociedade na qual está inserida, devendo estar constantemente permeada com o espírito de arte, história e ciência.

Quando Illich questiona qual seria a saída desta visão reducionista da escola, ressalta a importância do papel exercido pelos professores, sugerindo que eles desconstruam a relação de fornecedores (eles mesmos) e consumidores (alunos) do conhecimento. Caso contrário, o professor diplomado conduzirá o aluno a obter o seu próprio diploma num processo em que ambos saem frustrados, responsabilizando a falta de recursos por seus descontentamentos. Pelo fato de as instituições educativas estarem a serviço dos objetivos dos professores, as estruturas relacionais necessárias seriam as que se destinam a capacitar todo homem a definir-se a si mesmo pela aprendizagem e pela contribuição à aprendizagem dos outros, em uma relação mútua e construtiva. Mesmo afirmando que os professores estariam dispostos a derrubar as paredes das salas de aula para transformar toda a cultura numa grande escola, Illich sugere que se forneça ao aluno novas relações com o mundo ao invés de restringir o saber por meio do professor.

\section{Ver na educação suas verdadeiras relações}

Illich crê em um futuro promissor que dependerá de escolhas que incentivem uma vida de ação ao invés de uma vida de consumo, da capacidade do ser humano em produzir um estilo de vida que propiciará sua espontaneidade e sua independência ao invés da manutenção de um estilo de vida restrito ao fazer e desfazer, produzir e consumir. Portanto, o ser humano deve escolher entre ser rico em coisas ou ser livre 
para usá-las, apresentando como alternativa à dependência escolar não a utilização de recursos públicos para uma novidade que faça as pessoas aprenderem, mas sim pela criação de um novo estilo de relacionamento educacional entre o ser humano e o meio ambiente que o circunda.

Com isso, indica três propósitos para um bom sistema educacional: facilitar o acesso aos recursos necessários para o aprendizado daquilo que se queira efetivamente aprender (de forma prazerosa); capacitar aqueles que queiram partilhar seus conhecimentos e possibilitar que os demais interessados neste saber os encontrem; e oportunizar aos que queiram tornar públicos seus conhecimentos para que seus desafios sejam conhecidos. Neste contexto, a tecnologia pode estar tanto à disposição do ensino burocrático como a serviço da independência, restando-nos apenas questionar seus propósitos e finalidades.

Ao invés de rotular os recursos educacionais de acordo com as metas curriculares, Illich propõe abordagens que possibilitam aos estudantes acessar recursos para traçar suas próprias metas: reforçar uma sociedade inventiva e criadora, que se relacione com a natureza (essência) das coisas e não por suas aparências (industrializadas), disponibilizando artefatos e processos de reconhecido valor educativo para que o jovem possa assumir sua responsabilidade na vida da comunidade; viabilizar o compartilhamento de habilidades não restritas ao reconhecimento público por certificados emitidos, pois estes tendem a abolir a liberdade de educação à medida que confinam o conhecimento; possibilitar o encontro de pessoas com interesses específicos, sejam eles quais forem, para que possam se complementar, estabelecendo uma rede de comunicação que propicia o direito do indivíduo de se fazer ouvido em diversos grupos; incentivar que os conhecimentos sobre a aprendizagem humana (e sobre os recursos educacionais) englobem também os saberes baseados na experiência em qualquer tipo de pesquisa que, por prazer, reafirma o produtivo lazer (em grego schole) na relação horizontalizada entre professores e alunos.

Com isso, como a educação que nos faz necessitar do produto está incluída no preço do produto, o autor conclui que o grande ganho com a desescolarização da sociedade refere-se à não distinção entre economia, educação e política sobre a qual descansa convenientemente a ordem do mundo vigente para a perpétua estabilidade das nações. Em última instância, Illich salienta que a alternativa para os funis escolásticos é um mundo tornado transparente pelas verdadeiras teias de comunicação para que se 
possa resgatar a dimensão humana diante do processo planejado (ou padronizador) que se institucionalizou.

\section{REFERÊNCIAS}

DEWEY, Jonh. Democracia e educação. São Paulo: Nacional, 1952.

FREIRE, Paulo. Pedagogia da autonomia: saberes necessários à prática educativa. São Paulo: Paz e Terra, 1996.

GRAMSCI, Antonio. Os intelectuais e a organização da cultura. Rio de Janeiro: Civilização Brasileira, 1968. 